\title{
Prevalence and types of refractive errors, and spectacle coverage in Sri Lankan adults: The Sri Lanka National Survey of Blindness and Visual Impairment
}

\author{
C Gilbert ${ }^{1}$, G V S Murthy ${ }^{1,2}$, E Schmidt ${ }^{3}$, K Edussuriya ${ }^{4}$, R P Kumara ${ }^{5}$, S A H K Wimalarathne ${ }^{5}$, A H \\ Athapattu $^{6}$, M D Priyangani ${ }^{6}$, K R T C Bandara ${ }^{6}$, C Rathnayake ${ }^{6}$, Y G U Jayarathne ${ }^{6}$, H B Pant ${ }^{2}$ on \\ behalf of the Sri Lanka National Blindness, Visual Impairment and Disability Steering Committee \\ and Survey Team ${ }^{7}$
}

\begin{abstract}
Introduction Uncorrected refractive errors are the commonest cause of visual impairment globally. Despite this, the proportion of affected individuals who wear spectacles can be low, particularly in low and middle-income countries. No data were available for Sri Lanka.

Objectives To estimate the prevalence of refractive errors and investigate their risk factors among adults aged 40 years and above. Another purpose was to calculate spectacle coverage and identify subgroups with low coverage.

Methods Cluster random sampling was used to obtain a nationally representative sample. Presenting distance visual acuity was measured using a logMAR chart, with distance spectacle correction if usually worn. All underwent autorefraction and an optician measured best-corrected visual acuity after subjective refraction. Participants who had undergone cataract surgery were excluded. Spectacle coverage was assessed amongst participants with a visual acuity of $<6 / 12$ in the better eye due to refractive error who attended the examination site with spectacles.
\end{abstract}

Results 5,779/6,713 (86.1\%) enumerated adults were examined; 5,179 had refraction data. $67 \%$ had a refractive error: hyperopia $49.6 \%$; myopia $17.4 \%$. Refractive errors increased with age. Being aged 60 years and above and Sinhala ethnic group were independent risk factors. Spectacle coverage was $17.7 \%$ overall, being lower in females and the non- literate. Based on the findings, 1.66 million adults require spectacles for distance correction.

Conclusions Refractive errors are very common in Sri Lankan adults, and there is a large unmet need for spectacles. Affordable services for refractive errors need to be scaled up, focusing on the most underserved subgroups in the population.

Ceylon Medical Journal 2018; 63 (S2): s33-s39

DOI: http://doi.org/10.4038/cmj.v63i5.8740

\section{Introduction}

The Global Burden of Disease (GBD), Risk Factors and Injury Study, estimated that in 2010 there were 6.8 million people who were blind from uncorrected refractive errors [95\% confidence interval (CI) 4.7-8.8 million] and a further 101.2 million (95\% CI 87.9-125.5 million) who were visually impaired. Uncorrected refractive errors were responsible for $20.9 \%$ of all blindness and $52.9 \%$ of all moderate and severe visual impairment in 2010 [1]. Despite the very large number of people affected, spectacle coverage, which assesses the extent to which the need for spectacle correction for distance visual acuity has been met, remains low, particularly in low and middle income countries, being only $1.7 \%$ in a survey of adults in Tanzania [2]. It was only $25.2 \%$ in adults in Bangladesh [3], and $29.5 \%$ in adults in India [4]. Studies have also demonstrated

\begin{abstract}
${ }^{1}$ Department of Clinical Research, London School of Hygiene and Tropical Medicine, London, United Kingdom, ${ }^{2}$ Indian Institute of Public Health, Hyderabad, Public Health Foundation of India, Hyderabad, India, ${ }^{3}$ Sightsavers, Haywards Health, United Kingdom, ${ }^{4}$ Department of Ophthalmology, General Hospital, Kandy, Sri Lanka, ${ }^{5}$ Survey Ophthalmologists, National Blindness, Visual Impairment and Disability Survey, Sri Lanka, ${ }^{6}$ Survey Optometrists, National Blindness, Visual Impairment and Disability Survey, Sri Lanka, ${ }^{7}$ In addition to the above, other members of the Sri Lanka National Blindness, Visual Impairment and Disability Survey Team: Palitha Mahipala, Asela Pradeep Abeydeera, Ahamed Jeza, KMK Gamage, Champa Banagala, Saman Senanayake, Sunil Fernando, Lakmini Dissanayake, Nirmi Vitharana, Nimal Edirisinghe, Sunil Settinayake, Mr. Souvik Bandhopadhyaya, Mr. Mahesh Dorairaj, Sandeep Bhuttan.
\end{abstract}

Correspondence: GVSM, e-mail: <Gvs.Murthy@lshtm.ac.uk>. Received 19 February 2018 and revised version accepted 23 June 2018.

(i) This is an open-access article distributed under the terms of the Creative Commons Attribution License, which permits unrestricted use, distribution, and reproduction in any medium, provided the original author and source are credited. 
inequality in access to spectacles; for example in a study in Pakistan spectacle coverage was $10.2 \%$ among adults living in affluent areas compared with $6.7 \%$ and $4.4 \%$ in areas classified as moderately developed and poor respectively [5].

A recent systematic review and meta-analysis of data on the prevalence of myopia, defined as refractive error of minus 0.5D or more, used papers published since 1995 . The findings were used to estimate the number of individuals with myopia in 2000 and to extrapolate the findings to the year 2050 [6]. The data were presented using the country groupings employed by the GBD project, and assumptions were made for countries or locations within countries, which lacked data. In the year 2000 there were an estimated 1,406 (95\% CI 932-1932) million people with myopia i.e., almost a quarter of the world's population $(22.9 \%)$. The number is projected to increase to $4,758(95 \%$ CI 3,620-6,065) million by the year 2050 , affecting almost half of the world's population (49.8\%). The number of individuals with high myopia is projected to increase from 163 million to 938 million over the same period. In the Southeast Asia region, which includes Sri Lanka, the prevalence of myopia in all ages was estimated to be $33.8 \%$ in 2000 , expected to increase to $62 \%$ by 2050 .

Given the projected increase in the number of people who will become myopic, it is important that countries assess the magnitude of visual impairment due to uncorrected refractive errors, including that due to myopia, and the extent to which the current need for spectacle correction is being met. The purpose of this paper is to present findings on the prevalence and types of refractive error, and the proportion of the need for spectacles for distance correction that is currently being met, among individuals aged $\geq 40$ years, who were examined in the Sri Lanka National Survey of Blindness, Visual Impairment and Disability.

\section{Methods}

A detailed description of the methodology is presented in another paper in this Special Issue. Details of relevance to refractive errors are presented below.

\section{Sample size calculation and sampling strategy}

The following parameters were used to calculate the sample size for the survey: prevalence of blindness (presenting vision) among those aged $\geq 40$ years $-2.5 \%$; confidence interval - 95\%; allowable error - 0.02 ; precision $-80 \%$; design effect -1.5 and a response rate of $85 \%$.

The original sample size to be recruited was 6,600 , with 100 individuals being examined in 66 locations across the country. Two clusters were added to ensure that each district had at least one cluster (total 68). It was expected that this sample would provide accurate estimates of the national magnitude of blindness and visual impairment, and on the prevalence and types of refractive errors. The survey was powered for national level estimates and so does not give accurate estimates at district level.

\section{Survey procedures}

During enumeration, all eligible individuals invited to participate in the survey were requested to wear or bring their spectacles for distance correction to the examination site, if these were available.

After individuals had been recruited and written informed consent obtained, an optometrist measured presenting visual acuity (PVA) in each eye using a LogMAR tumbling $\mathrm{E}$ chart at 4 meters in a well lit location, with correction if usually worn. Whether they were wearing spectacles or not was recorded. Individuals had to read at least 4 out of the five optotypes on a visual acuity line to be considered as able to read that level of visual acuity (i.e. $6 / 6,6 / 12,6 / 60$ etc.).If an individual could not see any letters at 4 metres, they were retested at 1 metre. If they could not see any letters at 1 metre, they were assessed, by an ophthalmologist for finger counting or light perception. All individuals underwent automated refraction (Topcon KR 8000) by an optometrist who used the findings as the basis for subjective refraction. PVA and best corrected VA (BCVA) were recorded for each eye. The refractive error was recorded if the VAimproved by two or more lines of VA with refraction. The autorefractor was calibrated every day.

All individuals with a PVA of $<6 / 12$ in the better eye were referred to an ophthalmologist for detailed examination which included slit lamp examination and dilated examination of the posterior segment with indirect ophthalmoscopy and fundus imaging. A cause of visual loss was assigned to each eye using standard methods recommended by the World Health Organization (WHO) [7], and the cause in one eye was selected as the cause for the individual using the same standard methods, wherein firstly all disorders contributing to visual loss in each eye were recorded, followed by selection of the main cause for each eye based on the primary cause for loss of vision. The method is explained in detail in the companion paper on survey methods in this issue of the journal.

\section{Definitions}

The definitions of myopia and hyperopia used the spherical equivalent (SE) i.e., the spherical correction plus half the cylindrical correction. Individuals who had undergone cataract surgery were removed from the analysis. All analyses used the findings in right eyes, as in other studies.

Low myopia was defined as a SE of more than -0.5 dioptres (D) to $-5.0 \mathrm{D}$, and high myopia as more than $-5.0 D$. Low hyperopia was defined as a SE of more than +0.5 dioptres (D) to $+2.0 \mathrm{D}$, Moderate hyperopia as SE of more than $+2.0 \mathrm{D}$ to $+5.0 \mathrm{D}$ and high hyperopia as more than $+5.0 \mathrm{D}$. Astigmatism was defined as a cylinder of more than $0.75 \mathrm{D}$. 
Spectacle coverage was defined as the proportion of the need for spectacle correction for distance vision that had been met at the 6/12 level. The following formula was used: met need / (met need + unmet need) x100, expressed as a percentage. Met need was the number of individuals whose presenting visual acuity with spectacles was $\geq 6 / 12$ who had an uncorrected VA of $<6 / 12$. Unmet need was all those with a PVA of $<6 / 12$ in the better eye where uncorrected RE was the main cause of visual loss, even if they were wearing distance glasses.

\section{Data management}

All data recording sheets were checked for completeness at the end of each day. Data were entered into a dedicated Access database which had built-in range and consistency checks, by an experienced data entry operator, and entries were checked by a second data officer.

Descriptive analyses were undertaken to estimate the age-adjusted prevalence and type of refractive errors. Univariate analyses were undertaken to explore associations between socio-demographic variables (including age, sex, rural/urban residence, literacy level, ethnic group and province) by type of refractive error. Variables which were significant at a level of 0.2 or less were included in the multivariable analyses to identify independent risk factors.

Participants who had undergone cataract surgery on right eyes were removed and so data were not included for 152 individuals $(2.6 \%)$.

\section{Results}

A total of 5,779 adults among the 6,713 enumerated were examined (overall response rate $86.1 \%$ ). Response rates were higher amongst older participants and females. Response rates by Province and by urban / rural residence were similar (range $84.7-87.9 \%$ and $83.7-86.4 \%$ respectively). Those who were not literate were more likely to be examined than those with primary education or above (93.0\% not literate; $80.9 \%$ graduates and above). After excluding those who had undergone cataract surgery, data were available on refractive errors for 5,179 right eyes (i.e., $89.6 \%$ of those examined).

\section{$\underline{\text { Prevalence and types of refractive errors }}$}

Using the spherical equivalent, two thirds of participants had a refractive error (67.0\%): almost half of the survey participants were hyperopic (49.2\%) and $17.4 \%$ had any degree of myopia (Table 1). High myopia affected $2.1 \%$ of individuals, while High hyperopia was present in $0.42 \%$ of the study population. Among those with a refractive error, $44.7 \%$ had astigmatism. Myopia and astigmatism were more common in males (myopia: $16.4 \%$ in males, $14.3 \%$ in females; astigmatism $48.8 \%$ in males, $42.2 \%$ in females) but hyperopia was more common in females (56.7\% in females, $47.0 \%$ in males). The prevalence of all types of refractive errors tended to increase with age.

\section{$\underline{\text { Risk factors for refractive errors }}$}

\section{Myopia:}

A "U-shaped" distribution of low myopia was found with age, as the prevalence was lowest in the group aged 40-49 years and higher in the older age groups (Table 2).

In univariate analysis there were no significant sex differences in the likelihood of having myopia of any severity; the odds of myopia however, were higher in older age groups $(60+$ years $)$ and among those who were not literate (OR 2.5; 95\% confidence interval (CI) 1.3-4.7). Individuals from the Sinhala ethnic group were also more likely to be myopic (OR 1.6; 95\% CI 1.3-1.9). In multivariable analysis the following variables were independent risk factors for myopia: age $60+$ years and belonging to the Sinhala ethnic group (OR 1.7; 95\% CI: 1.3-2.3).

\section{Hyperopia:}

In univariate analysis males, those who were not literate and those belonging to the Sinhala ethnic group were less likely to have hyperopia (OR 0.8: 95\% CI: 0.7-0.9 and OR 0.5 ; 95\% CI: 0.3-0.9, OR 0.7; 95\% CI 0.6-0.8 respectively), while individuals aged 50-69 had higher odds of hyperopia than those in the youngest group (Table 2). In multivariable analysis male sex, younger age (40-49 years) and Sinhala ethnic group were independent protective factors for hyperopia.

\section{$\underline{\text { Astigmatism }}$}

In univariate analysis males had higher odds of astigmatism (OR 1.3; 95\% CI 1.2-1.5) and astigmatism was lower in all older age groups compared with those age 40-49 years. Similar results were found in multivariable analysis.

There are estimated to be 1.660 (range 1.658-1.663) million adults in Sri Lanka who are visually impaired from uncorrected refractive errors $(<6 / 12$ in the better eye), using the prevalence of visual impairment and proportionate cause of visual impairment due to refractive errors) from the present survey and the population data for the year 2014, of whom $58 \%$ are female.

\section{Spectacle coverage}

The proportion of individuals with a significant refractive error, defined as a visual acuity of $<6 / 12$ in the better eye due to refractive error, who attended the examination site with the correct distance correction was only $17.7 \%$ (i.e., 223/1309) (Table 3). Coverage was lower in females than males and among rural dwellers than urban, but the differences were not statistically significant (15.2\% vs $20.2 \%$ and $16.3 \%$ vs $22.0 \%$, respectively). There was a marked trend in spectacle coverage by level of education, increasing from only $4.9 \%$ amongst those who were not literate to $45.5 \%$ amongst those educated to graduate level or above $(\mathrm{p}<0.001)$. Spectacle coverage was lowest in the Northern Province (13.0\%) and highest in the Western Province $(22.7 \%)$. 
Table 1. Prevalence and types of refractive errors

\begin{tabular}{|c|c|c|c|c|c|c|c|c|c|c|c|c|c|c|c|c|c|c|c|}
\hline \multirow{4}{*}{$\begin{array}{l}\text { Age group } \\
\& \text { sex }\end{array}$} & \multirow{4}{*}{$N$} & \multicolumn{4}{|c|}{ Myopia } & \multicolumn{6}{|c|}{ Hyperopia } & & & & & \multicolumn{2}{|c|}{ Astigmatism } & \multicolumn{2}{|c|}{ Emmetropia } \\
\hline & & \multicolumn{2}{|l|}{ Low } & \multicolumn{2}{|c|}{ High } & \multicolumn{2}{|c|}{ Total } & \multicolumn{2}{|l|}{ Low } & \multicolumn{2}{|c|}{ Moderate } & \multicolumn{2}{|c|}{ High } & \multicolumn{2}{|c|}{ Total } & & & & \\
\hline & & \multicolumn{2}{|c|}{$\begin{array}{l}>-0.5 \mathrm{D} \text { to } \\
<=-5.0 \mathrm{D}\end{array}$} & \multicolumn{2}{|c|}{$>-5.0 D$} & & & \multicolumn{2}{|c|}{$\begin{array}{l}>+0.5 D \text { to } \\
<=+2.0 D\end{array}$} & \multicolumn{2}{|c|}{$\begin{array}{l}>+2.0 \mathrm{D} \text { to } \\
<=5.0 \mathrm{D}\end{array}$} & \multicolumn{2}{|c|}{$\begin{array}{l}+ \\
5 . O D\end{array}$} & & & \multirow{2}{*}{\multicolumn{2}{|c|}{$>+0.75 D$}} & & \\
\hline & & $\mathrm{N}$ & $\%$ & $\mathrm{~N}$ & $\%$ & $\mathrm{~N}$ & $\%$ & $\mathrm{~N}$ & $\%$ & $\mathrm{~N}$ & $\%$ & $\mathrm{~N}$ & $\%$ & $\mathrm{~N}$ & $\%$ & & & & \\
\hline \multicolumn{20}{|l|}{ Female } \\
\hline $40-49$ & 1063 & 110 & 10.3 & 8 & 0.8 & 118 & 11.1 & 368 & 34.6 & 29 & 2.7 & 0 & 0.0 & 397 & 37.3 & 720 & 67.7 & 548 & 51.6 \\
\hline $50-59$ & 1023 & 70 & 6.8 & 17 & 1.7 & 87 & 8.5 & 502 & 49.1 & 184 & 18.0 & 1 & 0.1 & 687 & 67.1 & 349 & 34.1 & 249 & 24.3 \\
\hline $60-69$ & 680 & 107 & 15.7 & 29 & 4.3 & 136 & 20.0 & 252 & 37.1 & 193 & 28.4 & 1 & 0.1 & 446 & 65.6 & 160 & 23.5 & 98 & 14.4 \\
\hline 70-79 & 230 & 69 & 30.0 & 7 & 3.0 & 76 & 33.0 & 73 & 31.7 & 45 & 19.6 & 0 & 0.0 & 118 & 51.3 & 45 & 19.6 & 36 & 15.7 \\
\hline $80+$ & 51 & 16 & 31.4 & 2 & 3.9 & 18 & 35.3 & 14 & 27.5 & 9 & 17.6 & 0 & 0.0 & 23 & 45.1 & 13 & 25.5 & 10 & 19.6 \\
\hline All ages & 3047 & 372 & 12.2 & 63 & 2.1 & 435 & 14.3 & 1254 & 41.2 & 474 & 15.6 & 2 & 0.1 & 1730 & 56.8 & 1287 & 42.2 & 941 & 30.9 \\
\hline \multicolumn{20}{|l|}{ Male } \\
\hline $40-49$ & 612 & 81 & 13.2 & 3 & 0.5 & 84 & 13.7 & 145 & 23.7 & 11 & 1.8 & 0 & 0.0 & 156 & 25.5 & 458 & 74.8 & 372 & 60.8 \\
\hline $50-59$ & 755 & 65 & 8.6 & 9 & 1.2 & 74 & 9.8 & 397 & 52.6 & 58 & 7.7 & 1 & 0.1 & 456 & 60.4 & 334 & 44.2 & 225 & 29.8 \\
\hline $60-69$ & 542 & 98 & 18.1 & 12 & 2.2 & 110 & 20.3 & 222 & 41.0 & 83 & 15.3 & 3 & 0.5 & 308 & 56.8 & 172 & 31.7 & 124 & 22.9 \\
\hline $70-79$ & 175 & 59 & 33.7 & 3 & 1.7 & 62 & 35.4 & 47 & 26.9 & 21 & 12.0 & 0 & 0.0 & 68 & 38.9 & 65 & 37.1 & 45 & 25.7 \\
\hline $80+$ & 48 & 17 & 35.4 & 3 & 6.3 & 20 & 41.7 & 10 & 20.8 & 9 & 18.7 & 0 & 0.0 & 19 & 39.6 & 12 & 25.0 & 9 & 18.8 \\
\hline All males & 2132 & 320 & 15.0 & 30 & 1.4 & 350 & 16.4 & 821 & 38.5 & 182 & 8.5 & 4 & 0.2 & 1007 & 47.2 & 1041 & 48.8 & 775 & 36.4 \\
\hline Total & 5179 & 692 & 13.4 & 109 & 2.1 & 801 & 15.5 & 2103 & 40.6 & 665 & 12.8 & 22 & 0.4 & 2790 & 53.9 & 2516 & 48.6 & 185 & 35.9 \\
\hline
\end{tabular}

Table 2. Univariate and multi-variate analysis of risk factors for different types of refractive error

\begin{tabular}{|c|c|c|c|c|c|c|c|c|c|c|c|c|c|}
\hline \multirow[t]{3}{*}{ Variables } & & \multicolumn{4}{|c|}{ Myopia $(>-0.5 \mathrm{D})$} & \multicolumn{4}{|c|}{ Hyperopia $(>+0.5$ to $+13.5 \mathrm{D})$} & \multicolumn{4}{|c|}{ Astigmatism $(>-0.75 \mathrm{D}$ to $+0.75 \mathrm{D})$} \\
\hline & & \multicolumn{2}{|c|}{ Univariate } & \multicolumn{2}{|c|}{ Multivariate } & \multicolumn{2}{|c|}{ Univariate } & \multicolumn{2}{|c|}{ Multivariate } & \multicolumn{2}{|c|}{ Univariate } & \multicolumn{2}{|c|}{ Multivariate } \\
\hline & & $O R$ & $95 \% C I$ & $O R$ & $95 \% C I$ & $O R$ & $95 \% C I$ & $O R$ & $95 \% C I$ & $O R$ & $95 \% C I$ & $O R$ & $95 \% C I$ \\
\hline \multirow[t]{2}{*}{ Sex } & Female & Ref & & Ref & & Ref & & Ref & & Ref & & Ref & \\
\hline & Male & 1.2 & $1.0-1.5$ & 1.2 & $1.0-1.4$ & 0.8 & $0.7-0.9$ & 0.7 & $0.6-0.8$ & 1.3 & $1.2-1.5$ & 1.5 & $1.3-1.7$ \\
\hline \multirow[t]{5}{*}{ Age } & $40-49$ & Ref & & Ref & & Ref & & Ref & & Ref & & Ref & \\
\hline & $50-59$ & 0.6 & $0.5-0.7$ & 0.6 & $0.5-0.7$ & 3.1 & $2.6-3.6$ & 3.2 & $2.8-3.8$ & 0.3 & $0.2-0.3$ & 0.3 & $0.2-0.3$ \\
\hline & $60-69$ & 1.4 & $1.2-1.7$ & 1.4 & $1.1-1.7$ & 2.3 & $1.9-2.6$ & 2.5 & $2.1-3.0$ & 0.2 & $0.1-0.2$ & 0.2 & $0.1-0.2$ \\
\hline & $70-79$ & 3.1 & $2.4-4.0$ & 3.1 & $2.3-4.2$ & 1.1 & $0.9-1.4$ & 1.2 & $0.9-1.6$ & 0.2 & $0.1-0.2$ & 0.2 & $0.1-0.2$ \\
\hline & $80+$ & 3.7 & $2.4-5.8$ & 4.3 & $2.2-8.2$ & 0.9 & $0.6-1.4$ & 1 & $0.6-1.7$ & 0.1 & $0.01-0.2$ & 0.1 & $0.1-0.2$ \\
\hline \multirow[t]{2}{*}{ Residence } & Urban & & & & & & & & & & & & \\
\hline & Rural & 1.4 & $1.1-1.8$ & 1.3 & $0.9-1.8$ & 1.2 & $1.0-1.4$ & 1 & $0.8-1.3$ & 1.1 & $0.9-1.3$ & 1 & $0.8-1.3$ \\
\hline \multirow[t]{5}{*}{ Education } & $\begin{array}{l}\text { Graduate } \\
\text { or more }\end{array}$ & Ref & & Ref & & Ref & & Ref & & Ref & & Ref & \\
\hline & Secondary & 0.8 & $0.5-1.5$ & 0.91 & $0.5-1.7$ & 0.9 & $0.6-1.4$ & 0.9 & $0.5-1.2$ & 1.2 & 0.8-1.9 & 1.3 & $0.8-2.2$ \\
\hline & level & & & & & & & & & & & & \\
\hline & Primary level & 1.4 & $0.8-2.5$ & 1.20 & $0.6-2.4$ & 0.7 & $0.5-1.1$ & 0.7 & $0.4-1.2$ & 1 & $0.6-1.5$ & 1.4 & $0.8-2.5$ \\
\hline & Not literate & 2.5 & $1.3-4.7$ & 2.91 & $1.0-8.5$ & 0.5 & $0.3-0.9$ & 0.5 & $0.2-1.1$ & 0.6 & $0.4-1.0$ & 0.8 & $0.4-1.8$ \\
\hline \multirow[t]{9}{*}{ Province } & Sabaragamuwa & Ref & & Ref & & Ref & & Ref & & Ref & & Ref & \\
\hline & Eastern & 2.4 & $1.7-3.5$ & 2.2 & $1.4-3.5$ & 0.6 & $0.5-0.8$ & 0.7 & $0.5-1.1$ & 0.9 & $0.7-1.1$ & 0.9 & $0.6-1.2$ \\
\hline & North West & 1.8 & $1.2-2.6$ & 1.9 & $1.3-2.8$ & 0.7 & $0.5-0.9$ & 0.6 & $0.5-0.8$ & 1 & $0.8-1.3$ & 1.1 & $0.8-1.4$ \\
\hline & North & 1.7 & $1.2-2.5$ & 1.5 & $0.7-3.2$ & 0.8 & $0.6-1.0$ & 0.8 & $0.5-1.4$ & 0.8 & $0.6-1.1$ & 0.9 & $0.5-1.6$ \\
\hline & Central & 1.5 & $1.1-2.1$ & 1.2 & $0.8-1.7$ & 0.8 & $0.6-1.0$ & 0.9 & $0.7-1.2$ & 0.9 & $0.7-1.1$ & 0.8 & $0.6-1.1$ \\
\hline & North Central & 1.9 & $1.3-2.9$ & 1.9 & $1.2-2.9$ & 0.7 & $0.5-0.9$ & 0.8 & $0.5-1.1$ & 1.1 & $0.8-1.5$ & 1 & $0.8-1.4$ \\
\hline & Uva & 1.8 & $1.2-2.7$ & 2.1 & $1.4-3.3$ & 0.7 & $0.5-1.0$ & 0.6 & $0.4-0.8$ & 1 & $0.8-1.4$ & 1.1 & $0.8-1.6$ \\
\hline & Western & 1.2 & $0.9-1.6$ & 1.3 & $0.9-1.8$ & 1 & $0.8-1.2$ & 0.9 & $0.7-1.1$ & 0.8 & $0.7-1.0$ & 0.8 & $0.6-1.1$ \\
\hline & South & 1.1 & $0.7-1.8$ & 1.2 & $0.7-2.0$ & 1 & $0.7-1.5$ & 0.9 & $0.6-1.3$ & 0.7 & $0.5-1.0$ & 0.8 & $0.5-1.1$ \\
\hline \multirow[t]{3}{*}{ Ethnicity } & Tamil & Ref & & Ref & & Ref & & Ref & & Ref & & Ref & \\
\hline & Sinhala & 1.6 & $1.3-1.9$ & 1.7 & $1.3-2.3$ & 0.7 & $0.6-0.8$ & 0.7 & $0.6-0.8$ & 1 & $0.8-1.1$ & 1.1 & $0.9-1.3$ \\
\hline & Moor & 1 & $0.7-1.5$ & 0.8 & $0.4-1.4$ & 0.8 & $0.6-1.1$ & 1 & $0.7-1.5$ & 1.3 & $0.9-1.8$ & 1 & $0.7-1.6$ \\
\hline
\end{tabular}


Table 3. Spectacle coverage

\begin{tabular}{|c|c|c|c|c|c|}
\hline & & $\begin{array}{c}\text { Met need } \\
N=254\end{array}$ & $\begin{array}{c}\text { Met }+ \text { unmet need } \\
N=1435\end{array}$ & $\begin{array}{c}\text { Coverage } \\
\%\end{array}$ & \\
\hline \multirow[t]{2}{*}{ Sex } & Male & 105 & 517 & $20.3 \%$ & \\
\hline & Female & 149 & 918 & $16.2 \%$ & $\mathrm{X}^{2}-2.6 ; \mathrm{P}=0.11$ \\
\hline \multirow[t]{5}{*}{ Age } & $40-49$ & 23 & 151 & $15.2 \%$ & \\
\hline & $50-59$ & 86 & 554 & $15.5 \%$ & \\
\hline & $60-69$ & 107 & 534 & $20.0 \%$ & \\
\hline & $70-79$ & 34 & 169 & $20.1 \%$ & \\
\hline & $80+$ & 4 & 27 & $14.8 \%$ & $\mathrm{X}^{2}-3.7 ; \mathrm{P}=0.45$ \\
\hline \multirow[t]{2}{*}{ Residence } & Rural & 214 & 1248 & $17.1 \%$ & \\
\hline & Urban & 40 & 187 & $21.4 \%$ & $\mathrm{X}^{2}-1.4 ; \mathrm{p}=0.24$ \\
\hline \multirow[t]{4}{*}{ Education } & Not literate & 4 & 82 & $4.9 \%$ & \\
\hline & Primary level & 26 & 332 & $7.8 \%$ & \\
\hline & Secondary level & 214 & 999 & $21.4 \%$ & \\
\hline & Graduate and above & 10 & 22 & $45.5 \%$ & $\begin{array}{l}X^{2}-37.2 \\
p<0.0001\end{array}$ \\
\hline \multirow[t]{9}{*}{ Province } & Uva & 14 & 75 & $18.7 \%$ & \\
\hline & Eastern & 15 & 105 & $14.3 \%$ & \\
\hline & North West & 19 & 135 & $14.1 \%$ & \\
\hline & North & 14 & 108 & $13.0 \%$ & \\
\hline & Central & 41 & 282 & $14.5 \%$ & \\
\hline & North Central & 11 & 83 & $13.3 \%$ & \\
\hline & Sabaragamuwa & 23 & 114 & $20.2 \%$ & \\
\hline & Western Province & 104 & 459 & $22.7 \%$ & \\
\hline & South & 13 & 74 & $17.6 \%$ & $\mathrm{X}^{2}-10.46 ; \mathrm{p}=0.23$ \\
\hline \multirow[t]{3}{*}{ Ethnicity } & Tamil & 214 & 1165 & $18.4 \%$ & \\
\hline & Sinhala & 35 & 231 & $15.2 \%$ & \\
\hline & Moor & 5 & 39 & $12.8 \%$ & $\begin{array}{l}X^{2}-1.45 \\
P=0.48\end{array}$ \\
\hline Total & & 254 & 1435 & $17.7 \%$ & \\
\hline
\end{tabular}

\section{Discussion}

Evidence from all the low and middle-income countries shows that uncorrected refractive errors were the commonest cause of visual impairment [1]. The same was the case in Sri Lanka, where uncorrected refractive errors were responsible for $81.0 \%$ of mild visual impairment and $64.0 \%, 46.7 \%$ and $12.5 \%$ of moderate and severe visual impairment and blindness, respectively) (results presented in the causes of visual impairment paper in this issue).

Refractive errors of all types were common in Sri Lankan adults, affecting two thirds of the population aged $\geq 40$ years. Similar findings have been reported in Pakistan, Bangladesh and India $[8,9,10]$. In the national survey of adults aged $\geq 30$ years, in Pakistan (which used the same definitions as in this survey), the crude prevalence of myopia, hypermetropia and astigmatism were $36.5 \%$, $27.1 \%$, and $37 \%$, respectively [8]. In the Bangladesh national survey of adults aged $\geq 40$ years, $22.1 \%$ were myopic and $20.6 \%$ had hypermetropia [9]. In a survey of adults aged $\geq 40$ years in Tamil Nadu, south India, 30.7\% of individuals were myopic and $18.7 \%$ were hyperopic [10]. This is unlike the present study where the prevalence of hypermetropia was higher than the prevalence of myopia. Similar findings were reported from South Africa where it was observed that the prevalence of myopia was higher in males while prevalence of hypermetropia was higher in females [11]. In the present survey, the ratio of women to men among those examined is $1.43: 1$ and this could be responsible for the higher prevalence of hypermetropia.

Sex, age and ethnicity were the main factors associated with refractive errors. Ethnic differences have been reported in other surveys in the region. For example, in a survey of adults aged $\geq 40$ years in Singapore, Chinese participants were twice as likely to be myopic than Indians or Malays [12]. Most of these surveys used the same definition of myopia as in our study, but our definitions of hyperopia and astigmatism were different and so the data 
are not comparable. Other surveys from the South East Asia region, in Indonesia [13], Korea [14], Myanmar [15] did not use the same definitions making comparisons difficult.

The higher prevalence of myopia in the youngest age groups in the Sri Lanka survey compared to other studies suggests that the incidence may be increasing. However, a limitation of this study was that lens opacities were not graded using systems which can detect early nuclear sclerosis, and it is likely that some of the myopia in older age groups was index myopia. The " $U$ " shaped distribution of myopia has also been reported from a metaanalysis of population based data from other countries in Asia [16].

Over 1.5 million adults in Sri Lanka are visually impaired due to uncorrected refractive errors, with a greater number of affected females than males. Spectacle coverage was low overall, particularly amongst the poorly educated and in the north of the country. There have only been a few studies of spectacle coverage in Asian countries, with surveys in Bangladesh and Pakistan, which used similar definitions, reporting coverage rates of $25.2 \%$ in Bangladesh [3], and $15.1 \%$ in Pakistan [8] at the 6/12 level. In Bangladesh, the coverage was lower in females $(30.2 \%$ in men and $20.9 \%$ in women) while in Pakistan those who were not literate were five times less likely to have their need for spectacles met than those who were literate. A limitation of this study is that some individuals with distance correction did not bring them to the examination site, which led to an underestimation of spectacle coverage. Another limitation of the survey is that the prevalence of presbyopia was not estimated, nor was spectacle coverage for near correction assessed. Since lens opacities were excluded in the calculation of refractive errors, this may have increased the prevalence of myopia and the overall prevalence of refractive errors.

In conclusion, the survey showed that uncorrected refractive errors are a significant public health concern in Sri Lanka, which affects a significant proportion of the adult population. Coverage with spectacles however is low, particularly in women, rural residents and those with low levels of education levels. Although significant progress has been made to advance eye health services in the country, the ratio of optometrists/ophthalmic technicians to the population remains below the recommended standards.

To improve current spectacle coverage, and anticipating the increasing incidence of myopia, access to high quality refractive services, which are affordable for all need, to be scaled up, particularly in the population sub-groups and provinces where the coverage is lowest. Whilst factors associated with the increasing incidence have not been fully elucidated, there is increasing evidence that myopia in children is associated with less time spent outdoors [17], and preventive efforts need to be put in place to address this growing problem.

\section{Acknowledgements}

We acknowledge the support from the members of the Steering Committee, the Sri Lanka College of Ophthalmologists, the Vision2020 Secretariat, Ministry of Health \& Family Welfare, Sri Lanka, Sightsavers Country Office, Sri Lanka and all the supervisors and field investigators (Madhuni Wijepala, Subhashini Deshappriya, Rasika Damayanthi, Dinusha Sandamali, Ashanti de Silva, Chaturika Madushani, Menaka Rathnayake, Madusha Priyadarshini, Nadeesha Dilhani, Gaya Shanthi) and data entry operators (Sunethra Thennakoon, Kumuduni Sriyalatha) who worked with great diligence in collecting the data from the survey participants. We thank all the survey participants for giving us the time and opportunity to interact with them to collect critical data.

We would like to thank Sightsavers for financial support of the overall study and CBM for financial contribution to the disability component of the survey.

\section{Conflicts of Interest}

All authors declare that they do not have any conflicts of interest.

\section{References}

1. Naidoo KS, Leasher J, Bourne RR, et al. Vision Loss Expert Group of the Global Burden of Disease Study. Global Vision Impairment and Blindness Due to Uncorrected Refractive Error, 1990-2010. Optom Vis Sci 2016; 93: 227-34.

2. Mashayo ER, Chan VF, Ramson P, Chinanayi F, Naidoo KS. Prevalence of refractive error, presbyopia and spectacle coverage in Kahama District, Tanzania: a rapid assessment of refractive error. Clin Exp Optom 2015; 98: 58-64.

3. Bourne RR, Dineen BP, Huq DM, Ali SM, Johnson GJ. Correction of refractive error in the adult population of Bangladesh: meeting the unmet need. Invest Ophthalmol Vis Sci. 2004; 45: 410-7.

4. Marmamula S, Khanna RC, Narsaiah S, Shekhar K, Rao GN. Prevalence of spectacles use in Andhra Pradesh, India: rapid assessment of visual impairment project. Clin Exp Ophthalmol 2014; 42: 227-34.

5. Gilbert CE, Shah SP, Jadoon MZ, et al. Poverty and blindness in Pakistan: results from the Pakistan national blindness and visual impairment survey. BMJ 2008; 336: 29-32.

6. Holden BA, Fricke TR, Wilson DA, et al. Global prevalence of myopia and high myopia and temporal trends from 2000 through 2050. Ophthalmol 2016; 123: 1036-42.

7. World Health Organization, Geneva, 1988. Coding instructions for the WHO/PBL Eye Examination Record (Version III). WHO/PBL/88.1

8. Shah SP, Jadoon MZ, Dineen B, et al. Refractive errors in the adult Pakistani population: the national blindness and visual impairment survey. Ophthalmic Epidemiol 2008; 15: 183-90. 
9. Bourne RR, Dineen BP, Ali SM, Noorul Huq DM, Johnson GJ. Prevalence of refractive error in Bangladeshi adults: results of the National Blindness and Low Vision Survey of Bangladesh. Ophthalmology 2004; 111: 1150-60.

10. Raju P, Ramesh SV, Arvind H. et al. Prevalence of refractive errors in a rural South Indian population. Invest Ophthalmol Vis Sci 2004; 45: 4268-72.

11. Mashige KP, Jaggernath J, Ramson $\mathrm{P}$, et al. Prevalence of refractive errors in the INK area, Durban, South Africa. Optom Vis Sci 2016; 93: 243-50.

12. Pan CW, Zheng YF, Anuar AR, et al. Prevalence of refractive errors in a multiethnic Asian population: the Singapore epidemiology of eye disease study. Invest Ophthalmol Vis Sci 2013; 54: 2590-8.

13. Saw SM, Gazzard G, Koh D, et al. Prevalence rates of refractive errors in Sumatra, Indonesia. Invest Ophthalmol Vis Sci 2002; 43: 3174-80.

14. Rim TH, Kim SH, Lim KH, Choi M, Kim HY, Baek SH. Refractive errors in Koreans: The Korea National Health and Nutrition Examination Survey 2008-2012. Korean J Ophthalmol 2016; 30: 214-24.

15. Gupta A, Casson RJ, Newland HS, et al. Prevalence of refractive error in rural Myanmar: the Meiktila Eye Study. Ophthalmology 2008; 115: 26-32.

16. Pan CW, Dirani M, Cheng CY, Wong TY, Saw SM. The agespecific prevalence of myopia in Asia: a meta-analysis. Optom Vis Sci 2015; 92: 258-66

17. He M, Xiang F, Zeng Y, et al. Effect of Time Spent Outdoors at School on the Development of Myopia Among Children in China: A Randomized Clinical Trial. JAMA 2015; 314: 1142-8. 